\title{
Its time: a commentary on fear extinction in the human brain using $\mathrm{fMRI}$
}

\section{Article}

\section{Accepted Version}

Creative Commons: Attribution-Noncommercial-No Derivative Works 4.0

Morriss, J., Hoare, S. and van Reekum, C. M. (2018) Its time: a commentary on fear extinction in the human brain using fMRI. Neuroscience and Biobehavioral Reviews, 94. pp. 321322. ISSN 0149-7634 doi: https://doi.org/10.1016/j.neubiorev.2018.06.025 Available at https://centaur.reading.ac.uk/78184/

It is advisable to refer to the publisher's version if you intend to cite from the work. See Guidance on citing.

To link to this article DOI: http://dx.doi.org/10.1016/j.neubiorev.2018.06.025

Publisher: Elsevier

All outputs in CentAUR are protected by Intellectual Property Rights law, including copyright law. Copyright and IPR is retained by the creators or other copyright holders. Terms and conditions for use of this material are defined in the End User Agreement.

\section{www.reading.ac.uk/centaur}

\section{CentAUR}

Central Archive at the University of Reading 
Reading's research outputs online 
Commentary on fear extinction in the human brain: A meta-analysis of fMRI studies in healthy participants.

Jayne Morriss*, Shannon Hoare, and Carien M. van Reekum

Centre for Integrative Neuroscience and Neurodynamics

School of Psychology and Clinical Language Sciences

University of Reading

Reading

UK

* Correspondence:

Jayne Morriss

Centre for Integrative Neuroscience and Neurodynamics

School of Psychology and Clinical Language Sciences

University of Reading

Earley Gate, Whiteknights Campus

RG6 6AH Reading

United Kingdom

j.e.morriss@reading.ac.uk 


\begin{abstract}
The recent meta-analysis by Fullana et al. (2018) is both timely and significant, providing a vital milestone towards understanding the neural networks involved in threat extinction in humans. Fullana et al. (2018) examined both threat extinction and recall separately using sophisticated meta-analytic methods based on raw contrast maps. Importantly, the meta-analysis highlighted a lack of consistent activation across studies for key neural "players" in the threat extinction circuit: the amygdala and ventromedial prefrontal cortex (vmPFC). In the current commentary, we highlight reasons for which this key circuitry may not have resulted from this meta-analysis, and call for a 'gold standard' in the examination of threat extinction using fMRI.
\end{abstract}


Notably, the process of threat extinction is temporally sensitive and is therefore best observed across time. Activity in the amygdala and subsequent threat behaviour (e.g. electrodermal activity in humans and freezing in rodents) have been shown to gradually decrease to learned threat cues compared to learned safety cues across extinction (LaBar, Gatenby, Gore, LeDoux, \& Phelps, 1998; Repa et al., 2001) in both studies using human functional resonance imaging (fMRI) and single cell recording studies in rodents. Furthermore, in fMRI studies, increased activity in the vmPFC is found for the learned threat cue compared to the learned safety cue during late extinction learning (Milad et al., 2007), which has been thought to represent safety-learning.

Despite the strength of amygdala-ventromedial prefrontal cortex (vmPFC) findings in the extinction literature, the recent meta-analysis by Fullana et al. (2018) revealed little evidence for amygdala and vmPFC activation during extinction across studies. Fullana et al. (2018) suggested that the lack of amygdala and vmPFC activation observed in their meta-analysis of extinction may be attributed to: (1) less reliability of the extinction process within animals versus humans, (2) reduced anatomical resolution in human $\mathrm{fMRI}$, and (3) averaging across multiple trials. Whilst we don't disagree with these points, we think the third point needs to be examined in more detail. Here we highlight a crucial reason as to why amygdala and vmPFC findings may have not been observed in the Fullana et al's (2018) meta-analysis.

Surprisingly, in Fullana et al's (2018) meta-analysis learned threat versus safe cues were examined, as opposed to learned threat versus safe cues across time (e.g. early versus late) because, as specified in a footnote, the authors did not have enough data to make this comparison. Indeed, we examined the published studies included in the meta-analysis, and we were surprised to find that only 17 out of the 
25 published papers reported a time-based comparison during extinction. Moreover, 9 out of 17 of those that did use time-based comparisons were using less optimal variants of the contrast such as separate contrasts to examine the effect of condition during early and late extinction: early threat versus safety; late threat versus safety; early threat versus late threat. To capture the full interaction of condition by time, more appropriate and statistically powerful comparisons are to: (1) use regressors for both condition and time in the analysis e.g. Early (Threat - Safe) - Late(Threat Safe), or (2) include parametric regressors to examine linear changes over time (e.g. Molapour, Golkar, Navarrete, Haaker, \& Olsson, 2015).

Given the temporal sensitivity of the extinction process and that the majority of the studies used in the meta-analysis were relatively recent, it is concerning that time-based analyses were not identified as the 'gold standard'. We recognise that there may be other studies in the literature that have used time-based comparisons but were not shared with Fullana et al. (2018), and we could not examine the 6 unpublished studies in the meta-analysis. Nonetheless, the meta-analysis by Fullana et al. (2018) underlines the need for standardised examination of extinction across time, at least for: (1) understanding the concept of extinction in humans, (2) translating animal to human work, and (3) scientific rigour and replication purposes. We hereby call for future research to include the reporting of an appropriate timebased analysis of threat vs. safe cues, alongside an overall contrast of threat vs. safe cues. 


\section{References}

Fullana, M., Harrison, B., Soriano-Mas, C., Vervliet, B., Cardoner, N., Àvila-Parcet, A., \& Radua, J. (2016). Neural signatures of human fear conditioning: an updated and extended meta-analysis of fMRI studies. Molecular Psychiatry, 21(4), 500 .

LaBar, K. S., Gatenby, J. C., Gore, J. C., LeDoux, J. E., \& Phelps, E. A. (1998). Human amygdala activation during conditioned fear acquisition and extinction: a mixed-trial fMRI study. Neuron, 20, 937-945.

Milad, M. R., Wright, C. I., Orr, S. P., Pitman, R. K., Quirk, G. J., \& Rauch, S. L. (2007). Recall of fear extinction in humans activates the ventromedial prefrontal cortex and hippocampus in concert. Biological psychiatry, 62(5), 446-454.

Molapour, T., Golkar, A., Navarrete, C. D., Haaker, J., \& Olsson, A. (2015). Neural correlates of biased social fear learning and interaction in an intergroup context. Neuroimage, 121, 171-183.

Repa, J. C., Muller, J., Apergis, J., Desrochers, T. M., Zhou, Y., \& LeDoux, J. E. (2001). Two different lateral amygdala cell populations contribute to the initiation and storage of memory. Nature neuroscience, 4(7), 724-731. 